\title{
CINCUENTA PLANTAS DEL ENTORNO DE LA MAR CHICA
}

\author{
Ángel Manuel Hernández Cardona \\ Académico Correspondiente de la Real Academia de Medicina de Cataluña \\ amhernandezcardona@gmail.com
}

Resumen: En este artículo se estudian cincuenta plantas del entorno de la Mar Chica. De cada una de ellas se da una descripción original y se indica su hábitat $y$ distribución, así como el sitio donde se ha recolectado.

Palabras Clave: Mar Chica, Nador, Marruecos, plantas.

Abstract: In this article fifty plants from the surroundings of the Mar Chica lagoon are studied. For each one of them an original description is given and its habitat and distribution are indicated, as well as the place where it has been collected.

Keywords: Mar Chica, Nador, Morocco, plants.

\section{Introducción}

Durante cinco cursos (2000-2005), fui catedrático de biología y geología del Instituto Español Lope de Vega, de Nador (Marruecos). Además de la intensa labor docente desarrollada en este acreditado centro escolar, pude recorrer una gran parte de la Guelaya y estudiar su interesante flora y vegetación. Una de las zonas más recorridas fue la que circunda la Mar Chica. Incluso, en el año 2004, coordiné un grupo de trabajo interdisciplinario sobre la Mar Chica (Hernández, 2004), en el cual participaron los siguientes compañeros: Juana Alías, Ángel Arteche, Ana Carmona, Estefanía Espada, Genoveva González, María Granado, Juan Víctor Maldonado, Carlos Navarro, María Paz Sarasola, José Manuel Soria, Ahmed Teziti, María Trapiello y Diego Zambrano.

Para la realización de este trabajo, se han tenido en cuenta, sobre todo, las publicaciones especificadas en la bibliografía. Todas las plantas estudiadas están avaladas por pliegos de herbario. A este respecto, cabe decir que las recolecciones efectuadas han sido muy comedidas y que 
solo se han recogido muestras si la población de la planta herborizada era abundante.

\section{La Mar Chica}

La Mar Chica (en árabe Sebja Bu Areg y en francés Lagune de Nador) está situada en el norte de Marruecos, concretamente en la región del Rif y en la provincia de Nador. Se trata de una albufera con una salida al mar abierto, la Bocana. Su superficie es de 115 kilómetros cuadrados. Su mayor longitud es de 25 kilómetros y su anchura máxima de 7,5 kilómetros. Está separada del Mediterráneo por un cordón arenoso o manga de 25 kilómetros. Es la laguna más grande de Marruecos y una de las albuferas mayores de todo el Mediterráneo.

Las plantas del entorno de la Mar Chica son muy interesantes por las adaptaciones que presentan a la salinidad y a otros factores ecológicos propios del litoral. En las dunas litorales encontramos plantas adaptadas no solo a la salinidad, sino también a la inestabilidad del sustrato y paradójicamente a la sequía. En las marismas y suelos salinos inundables, la salinidad y la falta de oxigenación hacen que la flora esté limitada a unas pocas plantas especialmente adaptadas. Finalmente se debe señalar que en el Atalayón y en las colinas próximas a la albufera y a la ciudad de Nador hay una rica representación de especies mediterráneas meridionales.

Allium subvillosum Salzm. ex Schultes et Schultes fil. (liliáceas)

Planta herbácea con un bulbo ovoide o globoso de 10 a $18 \mathrm{~mm}$, revestido de una túnica foveolada, acompañado a veces por 2 o 3 bulbilos; de tallo cilíndrico, que puede alcalnzar $45 \mathrm{~cm}$ de altura; de hojas aplanadas, estrechas, ciliadas en el margen; de flores blancas, con los estambres de filamentos simples y anteras amarillas; de inflorescencias en umbela semiesférica; y de frutos en cápsula. Vive en pinares, claros del matorral y dunas costeras, siempre sobre sustratos arenosos o calizos. $\mathrm{Su}$ área de distribución abarca las regiones mediterránea y macaronésica. Encontré este peculiar ajo silvestre cerca del Fortín de la Restinga.

\section{Althaea longiflora Boiss. et Reuter (malváceas)}

Hierba anual, híspida, de hasta $40 \mathrm{~cm}$ de altura; de hojas inferiores crenadas y las superiores palmatilobuladas o palmatisectas; de flores de color rosado, solitarias y largamente pedunculadas, con un epicáliz muy 
desarrollado; y de frutos esquizocárpicos. Crece en yermos y lugares secos. Es exclusiva de la región mediterránea occidental. La recogí en el Atalayón.

\section{Asteriscus maritimus (L.) Less. (compuestas)}

Planta perenne, híspida, de tallos rastreros, leñosos, ramificados, que no sobrepasan los $20 \mathrm{~cm}$; de hojas alternas, enteras, marcadamente espatuladas; de capítulos tipo margarita, de color amarillo vivo en las lígulas y amarillo anaranjado en el disco central; y de frutos en aquenio, con vilano. Crece en roquedas y pedregales costeros. Se encuentra en toda la región mediterránea, siempre en el litoral. La recolecté cerca del Fortín de la Restinga, sobre el terreno compacto de dunas fosilizadas.

\section{Atractylis cancellata L. (compuestas)}

Hierba anual, ramificada, espinulosa, con pilosidad araneosa; de hojas lanceoladas o estrechamente espatuladas, con el margen más o menos dentado y con espínulas; de capítulos terminales, rodeados, a manera de involucro complementario, por un conjunto de hojas estrechas, pectinadas y espinescentes; y de frutos en aquenio. Vive en pastizales secos, claros de bosque y bordes de caminos. Se extiende por la región mediterránea y algunas islas del archipiélago canario. La recolecté en el Atalayón.

\section{Calicotome intermedia C. Presl. (leguminosas)}

Arbusto espinoso, de ramas alternas, de hojas trifolioladas y pecioladas, de flores amarillas, con el cáliz que al desarrollarse pierde la parte apical y queda una porción en forma de copa, y de frutos en legumbre. Se distingue de C. villosa (Poiret) Link, la otra especie presente en Marruecos, por los cálices seríceos, es decir, con pelos cortos, suaves y brillantes como la seda, y por las legumbres, igualmente seríceas, sin alas o solamente con dos alas estrechas. Crece en manchas y matorrales de lugares rocosos y soleados. Es una planta propia del norte de Áfirca y del sureste de la Península Ibérica. Recogí una muestra en el Atalayón.

\section{Campanula dichotoma L. (campanuláceas)}

Hierba anual, híspida; de tallos de 10 a $35 \mathrm{~cm}$, con pelos rígidos patentes y generalmente con ramificación dicótoma; de hojas basales pecioladas, que caen o se marchitan durante la antesis, y de hojas caulinares alternas, oblongas y más o menos dentadas; de flores azauladas o 
lilas, con la corola que sobrepasa mucho el cáliz, el cual presenta apéndices entre los lóbulos calicinos; y de frutos capsulares dehiscentes por poros laterales. El nombre científico indicado, dado por Linneo, prevalece sobre el de Campanula afra, debido a Cavanilles. Medra en pastizales secos y lugares áridos. Se encuentra en la mitad sur de la región mediterránea occidental y central, y alcanza las islas Canarias. La descubrí y recolecté en Sidi Yusef.

\section{Carrichtera annua (L.) DC. (crucíferas)}

Hierba anual, de hasta $40 \mathrm{~cm}$ de altura, híspida; de hojas bipinnatisectas; de flores dispuestas en racimos, con 4 pétalos amarillentos y con una nervadura violácea; y de frutos en silícula, los cuales constan de dos partes diferenciadas, la inferior, elipsoidal, corresponde al ovario y tiene 2 valvas, con varias costillas ornadas de pelos rígidos, y 2 lóculos, cada uno con 3 semillas; y la superior, correspondiente al estilo, es cocleariforme. Vive en campos áridos, bordes de caminos, herbazales nitrófilos y arenales marítimos. Es una planta de la región mediterránea y del suroeste de Asia. La herboricé cerca del Fortín de la Restinga.

\section{Centaurea seridis L. (compuestas)}

Hierba perenne, erecta o decumbente, de hasta $80 \mathrm{~cm}$ de envergadura; de tallos alados, poco ramificados; de hojas alternas, lobuladas; de capítulos gruesos, con flores rosadas o purpúreas, y con brácteas provistas de 5 a 11 espinas, patentes o dirigidas hacia abajo, de un bello color amarillo cobrizo y de aspecto bruñido; y de frutos en aquenio, con o sin vilano. Habita en herbazales y eriales, sobre suelos arenosos del litoral. Se extiende por la región mediterránea occidental y central. La encontré en una duna situada al norte de la Bocana.

\section{Cynomorium coccineum L. subsp. coccineum (cinomoriá- ceas)}

Planta parásita, sin clorofila, en forma de clava y de color rojo violáceo; de raíz tuberiforme provista de haustorios, a través de los cuales se nutre de las raíces de otras plantas; de tallo cilíndrico, carnoso pero endurecido, con hojas diminutas, escamosas; de flores numerosas situadas en la parte superior engrosada de la planta, de tamaño minúsculo y de perianto reducido, acompañadas de pequeñas brácteas, la mayoría unisexuales con un solo estambre; y de fruto en núcula. Vive en arenales y saladares del litoral o del interior, parasitando diferentes especies de 
plantas halófilas. Su área de distribución es mediterránea meridional, canaria, sahariana e irano-turaniana. La subespecie típica es la más extendida, quedando la subespecie sonaricum (Rupr.) L. Léonard relegada a zonas de Asia central. Es bastante frecuente en todo el lido de la Mar Chica, aunque solamente conservo un ejemplar de la parte norte de la Bocana, como parásita de Halimione portulacoides. Tradicionalmente se había incluido en la familia de las balanoforáceas, pero diversas particularidades morfológicas y fisiológicas aconsejan su inclusión en la segregada familia de las cinomoriáceas.

\section{Cyperus capitatus Vandelli (ciperáceas)}

Hierba perenne, glabra, glauca; con rizomas largos, gruesos, estoloníferos; con hojas de 2 a $6 \mathrm{~mm}$ de ancho; con flores hermafroditas, poco aparentes, sin perianto, situadas en la axila de glumas y formando espiguillas, las cuales se reúnen en inflorescencias globosas terminales que traen en su base de 3 a 6 brácteas largas, desiguales, dilatadas en su base; y con frutos en núcula. Es una planta propia de playas y dunas marítimas, que forma parte de comunidades arenícolas de la clase $\mathrm{Am}$ mophiletea. Se encuentra en todo el litoral de la región mediterránea y en zonas costeras atlánticas norteafricanas y europeas meridionales. $\mathrm{La}$ recolecté en Oulad Zahra. [1]

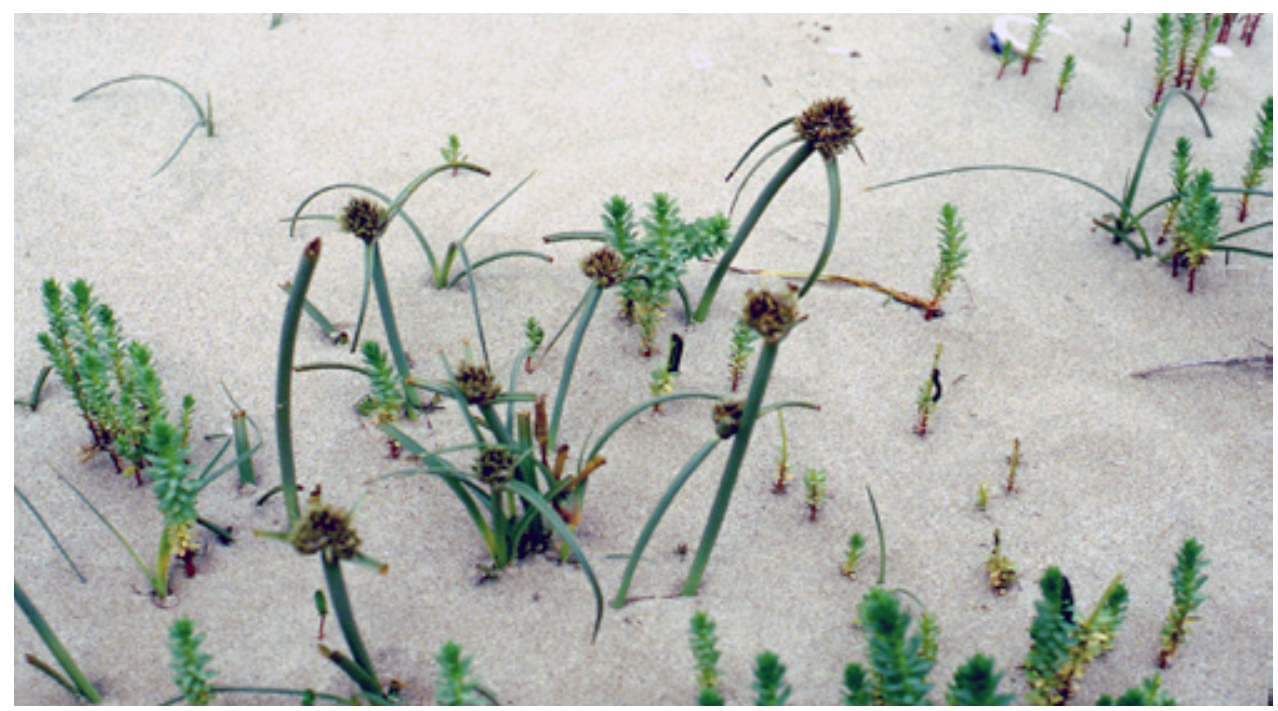

Fig.1. Cyperus capitatus 


\section{Echinops strigosus L. (compuestas)}

Hierba anual, robusta, espinulosa y con abundante pilosidad araneosa, normalmente con un solo tallo que puede alcanzar los $90 \mathrm{~cm}$ de alto; de hojas una o dos veces pinnatisectas, con los segmentos estrechos, de haz verdosa y de envés blanquecino; de capítulos alargados y reunidos en inflorescencias globosas grandes (de 35 a $80 \mathrm{~mm}$ de diámetro); y de frutos en aquenio provisto de vilano. Crece en taludes áridos, herbazales soleados y bordes de caminos. Es una especie de distribución iberomagrebí. La herboricé en el Atalayón.

\section{Echium plantagineum L. (boragináceas)}

Planta herbácea anual o, a veces, bienal, híspida, de tallos erectos o ascendentes; de hojas con pelos rígidos, las inferiores de contorno elíptico, pecioladas y con las venas muy marcadas, y las superiores lanceoladas y sésiles; de flores azules, con la corola infundibuliforme, de 20 a $30 \mathrm{~mm}$, apenas pelosa (solamente en el borde y junto a las venas), de la cual sobresalen un par de estambres; de inflorescencias cimosas, densas; y de frutos en núcula. Crece en campos, orillas de caminos y prados secos algo nitrificados. Se extiende por toda la región mediterránea y zonas próximas. La recogí en la parte sur de la manga de la Mar Chica, cerca del Fortín de la Restinga.

\section{Euphorbia falcata L. subsp. falcata (euforbiáceas)}

Hierba anual, glabra, a menudo con una cierta coloración rojiza; de tallos simples o ramificados, erectos o procumbentes; de hojas simples alternas, de forma obovada o espatulada; de inflorescencias complejas, cuyas unidades básicas, los ciatios, presentan unas glándulas con cuernos; las brácteas de las inflorescencias son ovales y con un mucrón muy aparente; el fruto es glabro y poco surcado; y las semillas son muy características, con 4 a 7 surcos trensversales en cada cara. Crece en campos, orillas de caminos y yermos. Su área de distribución ocupa la mitad sur de Europa, el norte de África y una buena parte de Asia occidental y central. La recogí en el Atalayón.

\section{Euphorbia terracina L. (euforbiáceas)}

Hierba perenne, glabra; de tallos simples o, muy a menudo, ramificados desde la base; de hojas lineares, lanceoladas u oblongas; de inflorescencias con glándulas provistas de cuernos finos; y de frutos y semillas lisos. Medra en dunas litorales, ramblas y eriales arenosos, generalmente 
en zonas costeras o poco alejadas del mar. Es una especie propia de la región mediterránea. La hallé y recogí en unos campos próximos a la aldea de Oulad Zahra.

\section{Euphorbia paralias L. (euforbiáceas)}

Hierba perenne, robusta, glabra y glauca; de tallos múltiples, leñosos en la base, de hasta $70 \mathrm{~cm}$ de altura; de hojas alternas, oblongas o cortamente lanceoladas, parcialmente imbricadas, de tal manera que no dejan ver el tallo; de inflorescencias terminales, con brácteas ovales y glándulas del ciatio en forma de media luna; de frutos marcadamente surcados, exsertos; y de semillas lisas, de color gris claro. Vive en arenales marítimos y es una planta característica de la vegetación de la clase Ammophiletea. Se extiende por todo el litoral de la región mediterránea y también por las costas atlánticas europeas, norteafricanas y macaronésicas. Está en toda la manga de la Mar Chica y la recolecté al norte y al sur de la Bocana. [2]

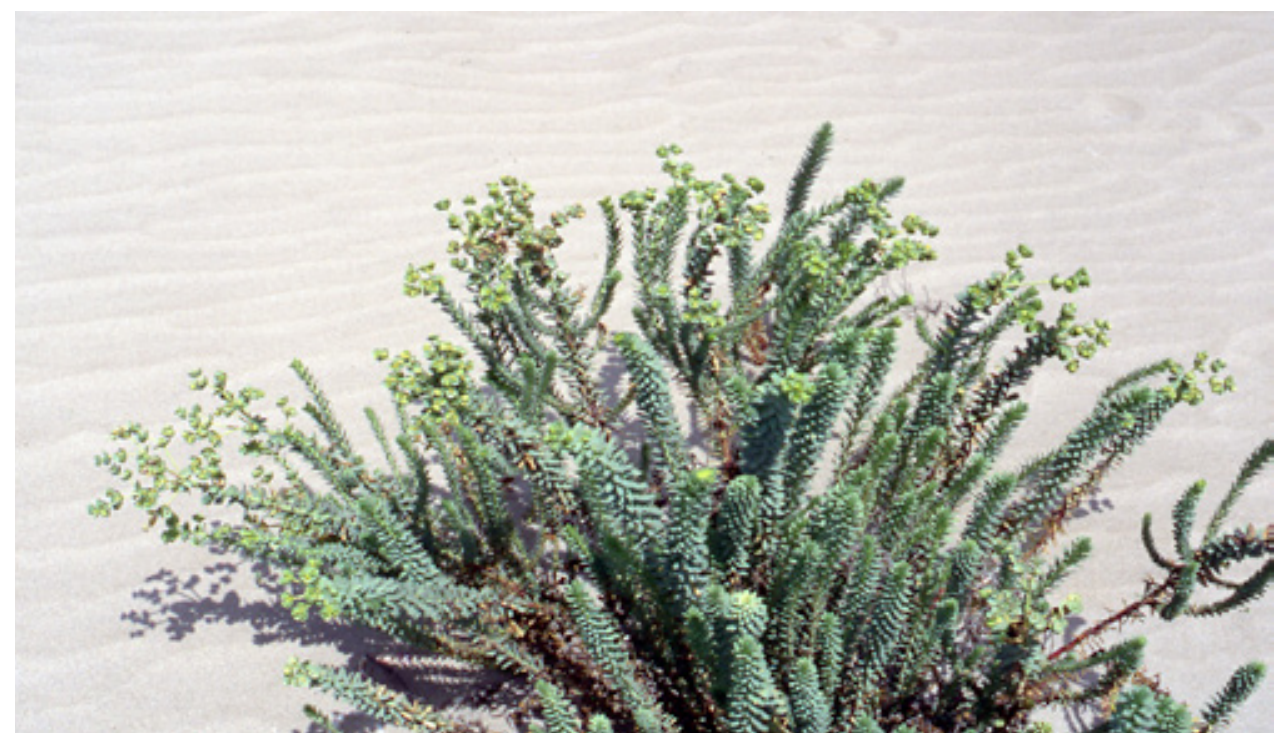

Fig.2. Euphorbia paralias

Fagonia cretica L. (cigofiláceas)

Hierba perenne, con tallos procumbentes, ramificados y estriados, de 10 a $40 \mathrm{~cm}$; de hojas opuestas, pecioladas y trifolioladas, con estípulas espinosas; de flores purpúreas o rosadas, solitarias en la axila de las hojas; $\mathrm{y}$ de frutos capsulares, en forma de peonza angulosa y cortamente ciliada 
en los márgenes, con cinco lóculos y con el estilo persistente, finalmente reflejos. Crece en terrenos áridos y pedregosos de la mitad sur de la región mediterránea. La herboricé en el Atalayón.

\section{Fumaria bastardii Boreau (papaveráceas)}

Hierba anual, que no suele sobrepasar los $20 \mathrm{~cm}$ de altura; de hojas varias veces pinnatisectas; de flores de más de $10 \mathrm{~mm}$, de color rosa pálido con el ápice oscuro, reunidas en racimos; y de frutos monospermos indehiscentes, redondos, que miden algo más de $2 \mathrm{~mm}$. Se cría en campos y eriales. Su área de distribución es atlántico-mediterránea. La recolecté junto al Fortín de la Restinga.

\section{Halimione portulacoides (L.) Aellen (quenopodiáceas)}

Mata o pequeño arbusto, decumbente, de color gris, con tallos que miden hasta $90 \mathrm{~cm}$; de hojas, al menos las inferiores, opuestas, oblongas, apenas pecioladas; de flores unisexuales, agrupadas en espigas, las masculinas con un perianto de 4 o 5 piezas, y las femeninas aclamídeas, pero con un par de bractéolas; y de frutos en aquenio, rodeados por las bractéolas acrescentes. Medra en marismas y arenales húmedos o anegados. Se encuentra en muchas costas europeas, norteafricanas y de otras partes del mundo. La he visto en los humedales de la parte sur de la Mar Chica y también a lo largo de la manga, tras la línea de dunas, allí donde el terreno queda encharcado. La tengo recogida de cerca del Fortín de la Restinga.

\section{Hedysarum spinosissimum L. (leguminosas)}

Planta herbácea anual, más o menos decumbente; de hojas compuestas de 4 a 8 pares de foliolos; de flores rosadas o blanquecinas; y de frutos en lomento, con segmentos orbiculares o anchamente elípticos, tomentosos y recubiertos de acúleos. Crece en yermos, espartales y dunas consolidadas. Es propia de la región mediterránea. La recolecté en la manga sur, junto al Fortín de la Restinga.

\section{Heliotropium curassavicum L. (boragináceas)}

Hierba perenne, postrada, ramificada y glabra; de hojas estrechamente lanceoladas, glaucas y ligeramente carnosas; de flores pequeñas, blancas, dispuestas en cimas escorpioides; y de frutos que se dividen en cuatro mericarpos. Se distingue fácilmente de sus congéneres $H$. europaeum L. y H. supinum L. por su carácter de hierba perenne, por ser lampiña, por su coloración glauca, por sus hojas estrechas, por sus frutos lobulados 
y porque al secarse se oscurece. Crece en baldíos del litoral. Es originaria de América y se encuentra naturalizada en algunas localidades de las regiones mediterránea y macaronésica. La recolecté en el Atalayón.

\section{Lathyrus clymenum L. (leguminosas)}

Hierba anual, trepadora, glabra; de tallos alados; de hojas superiores con 4-8 foliolos y con estípulas semihastadas; de flores rosadas o purpúreas, en grupos de 1 a 5 flores; y de frutos en legumbre. Una característica a destacar es la presencia en el estandarte de la flor de dos gibas o salientes digitiformes. Crece en prados secos, taludes soleados y márgenes herbosos. Es planta mediterránea, macaronésica y anatólica, frecuente en toda la Guelaya. La recogí en el Atalayón.

\section{Launaea arborescens (Batt.) Murb. (compuestas)}

Arbusto espinoso, de tallos erectos y muy ramificados, con ramas divaricadas; de hojas alternas, escasas, las caulinares estrechas, enteras o lobuladas, caedizas; de capítulos pedunculados, solitarios pero numerosos, estrechos (de 3 a $6 \mathrm{~mm}$ de anchura), con brácteas de margen escarioso y con lígulas amarillas; y de frutos en aquenio, de $3 \mathrm{~mm}$ o poco más, oblongos pero más anchos arriba que abajo, no estrechados en el ápice, parduscos, con 5 a 8 costillas y rugosos transversalmente. Crece en lugares áridos. Es un endemismo íbero-magrebí. Cogí una muestra al sur y no lejos de la Bocana.

\section{Lavandula dentata L. (labiadas)}

Mata o subarbusto de hojas lanceoladas y de margen crenado o dentado; de flores reunidas en inflorescencias especiformes largamente pedunculadas, provistas de brácteas, las superiores vistosamente violáceas; y de frutos en núcula. Crece en matorrales y pinares. Se extiende por todo el norte de África, islas Canarias, sur de la Penínula Ibérica, islas Baleares y Península Arábiga. La cogí en el Atalayón.

\section{Lavandula multifida L. (labiadas)}

Planta subarbustiva de hojas doblemente divididas, de contormo oval; de flores de color azul violáceo, intercaladas con brácteas elípticas y dispuestas en espigas terminales largamente pedunculadas; y de frutos en núcula. Crece en matorrales, ramblas y laderas soleadas. Se halla en el norte de África y sur de Portugal, España e Italia. La recolecté, junto con la anterior especie, en el Atalayón. 


\section{Limonium lobatum (L. fil.) Chaz. (plumbagináceas)}

Planta herbácea anual, con una roseta de hojas lobuladas y un escapo florífero de hasta $30 \mathrm{~cm}$ de altura, sin alas o, a menudo, con un par de alas estrechas que terminan en cada nudo con un apédice. Las flores, de color azul pálido por lo que atañe al cáliz y blanquecinas tirando a color crema por lo que respecta a la corola, están agrupadas en espigas densas, subtendidas por alas bracteiformes. Son características de esta especie las brácteas internas de ápice trilobulado, con la parte central continuada en dos apéndices rígidos uncinados, claramente visibles. Crece en taludes pedregosos del litoral o de zonas áridas del interior, sobre suelos salinos. Es una planta de la región mediterránea, que en el continente europeo solamente se encuentra en el sureste de la Península Ibérica. La recolecté en Marost.

\section{Linum strictum L. subsp. strictum (lináceas)}

Hierba anual, bastante alta (de hasta $50 \mathrm{~cm}$ ); de hojas estrechas y escabras en los bordes; de flores amarillas; y de frutos en cápsula. Prospera en prados secos, claros de bosque, pedregales y laderas soleadas. Se encuentra en la región mediterránea y zonas del Cercano Oriente. La subespecie strictum es más abundante en la región mediterránea occidental, mientras que la subespecie spicatum (Pers.) Nyman predomina en la parte oriental de su área de distribución. La herboricé en Marost.

\section{Lobularia libyca (Viv.) Webb et Berthol. (crucíferas)}

Hierba anual, provista de pelos naviculares; de tallitos decumbentes o ascendentes; de hojas estrechamente lanceoladas, atenuadas en la base a manera de peciolo; de flores blancas con 4 pétalos. agrupadas en racimos; y de frutos en silícula de forma elíptica, con las valvas aplanadas, que contienen de 2 a 6 semillas, generalmente 3 . Crece en dunas litorales, ramblas y campos arenosos. Se encuentra en el sur de la región mediterránea, en Canarias, en el norte de la región saharosindiana y en el extremo occidental de la región irano-turaniana. La hallé y recogí en Oulad Zahra, pedanía del municipio de Beni Ensar.

\section{Lobularia maritima (L.) Desv. subsp. maritima (crucíferas)}

Hierba parecida a la anterior, igualmente con pelos naviculares y de flores blancas en racimo, pero es perenne y sus frutos tienen las valvas convexas y contienen una sola semilla. Crece en dunas con- 
solidadas, eriales arenosos, claros de pinares y taludes soleados. Se extiende por toda la región mediterránea, en comarcas próximas a la costa, y también en la región macaronésica. Además, se halla naturalizada en el oeste de Europa y en algunas otras zonas templadas del globo. La subespecie típica es la común en toda el área de la planta, excepto en las islas Columbretes (provincia de Castellón), donde se cría la subespecie columbretensis R. Fern. La recogí cerca del Fortín de la Restinga.

\section{Lotus cytisoides L. (leguminosas)}

Hierba perenne, más o menos postrada, serícea; de hojas con 5 foliolos; de inflorescencias con unas pocas flores y con una hoja basal; de flores amarillas; y de frutos en silicua. Se diferencia de L. creticus L. (especie próxima de la cual a veces se la considera subespecie), por sus flores más pequeñas (de 9 a $13 \mathrm{~mm}$ ), por los dientes laterales del cáliz obtusos y más cortos, por la corola con el estandarte emarginado y la quilla curvada apicalmente, y por los frutos más cortos (de 10 a $25 \mathrm{~mm}$ ). Es una planta típica de la vegetación de los arenales marítimos (de la clase Ammophiletea). Se encuentra en el litoral de la región mediterránea. La detecté y recogí en diversos lugares de la barra litoral: Oulad Zahra, norte de la Bocana y Fortín de la Restinga.

\section{Lotus edulis L. (leguminosas)}

Hierba anual, de tallos erectos o ascendentes, de hojas con 5 foliolos, de flores amarillas y de frutos en legumbre, curvados y muy hinchados. Prospera en yermos, orillas de caminos y pastizales de la región mediterránea. La recolecté en las inmediaciones del Fortín de la Restinga.

\section{Mesembryanthemum crystallinum L. (aizoáceas)}

Planta herbácea anual, crasa, cubierta de papilas cristalinas; de tallos decumbentes, gruesos, de hasta $35 \mathrm{~cm}$; de hojas aplanadas, de forma oval, las inferiores opuestas y cortamente pecioladas, y las superioes alternas y sésiles; de flores solitarias axilares o agrupadas en pequeñas cimas terminales, pentámeras; y de frutos en cápsula de dehiscencia valvar. Vive en lugares arenosos, arcillosos o rocosos de tendencia árida, en el litoral marino. Oriunda de África del Sur, se ha naturalizado en diversas partes de la región mediterránea y de otras zonas templadas del globo. La he observado en muchos puntos 
de alrededor de la Mar Chica, aunque solamente la he recogido en el Atalayón y en Oulad Zahra. [3]

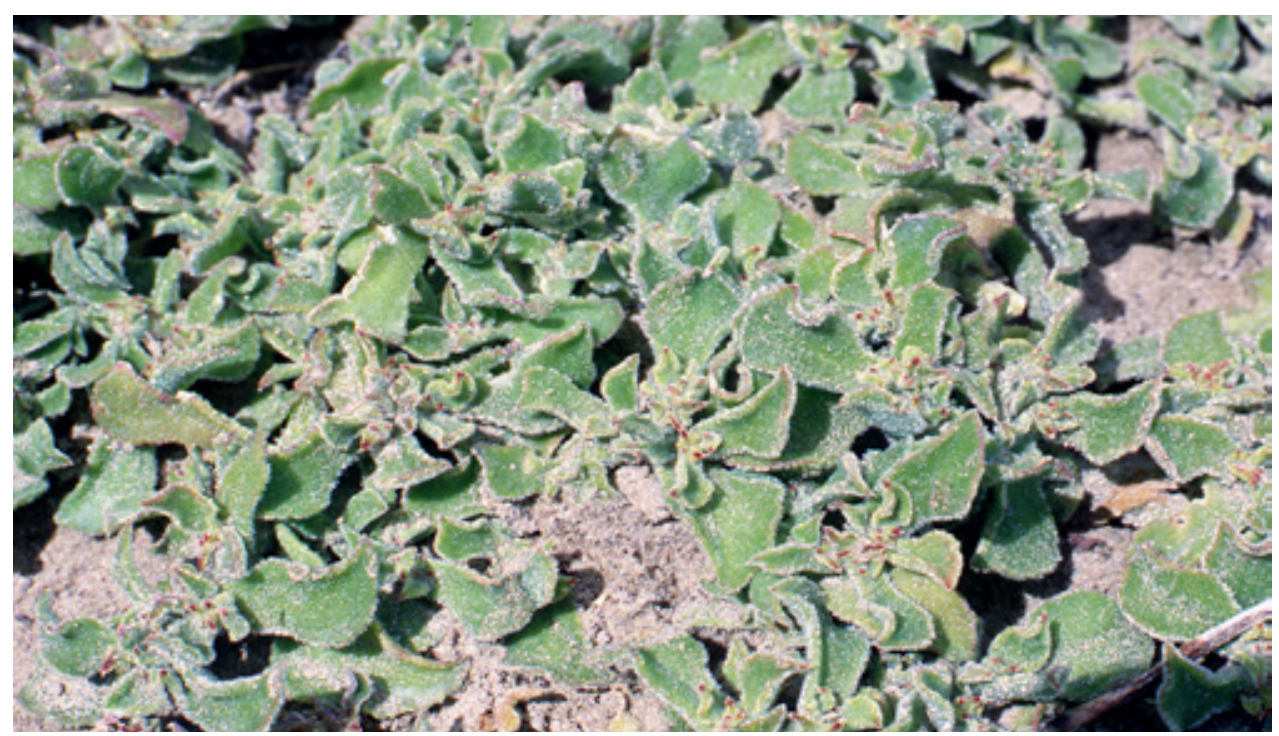

Fig.3. Mesembryanthemum crystallinum.

\section{Mesembryanthemum nodiflorum L. (aizoáceas)}

Planta herbácea anual, crasa, cubierta de papilas hialinas; de tallos postrados o ascendentes; de hasta $30 \mathrm{~cm}$; de hojas casi cilíndricas, las inferiores opuestas y las superiores alternas; de flores solitarias, pentámeras; y de frutos capsulares. Se da en terrenos arenosos, arcillosos y pedregosos del litoral. Se halla en el sur de Europa, islas macaronésicas, norte de África y suroeste de Asia. La he recolectado en el Atalayón y en las marismas de Kariat-Aberkane.

\section{Ononis pendula Desf. subsp. pendula}

Hierba anual, ramificada, de 12 a $35 \mathrm{~cm}$ de altura; de hojas trifolioladas o unifolioladas, con los foliolos obovados o cuneiformes, superiormente serrados; de flores con la corola más larga que el cáliz; y de frutos en legumbre. Respecto al color de las flores, el estandarte es rosado o azulado, mientras que la quilla y las alas son blanquecinas. Crece en herbazales, prados de anuales y claros del matorral. La especie se extiende por el noroeste de África, sur de España y Sicilia, pero la 
subespecie pendula es exclusivamente norteafricana. La hallé y recogí en el Atalayón.

\section{Paronychia argentea Lam. (cariofiláceas)}

Hierba perenne, de tallos postrados y ramificados; de hojas pequeñas, oblongas, glabras; de flores ocultas por brácteas plateadas, con los sépalos aristados, reunidas en glomérulos de más de $10 \mathrm{~mm}$ de diámetro; y de frutos en utrículo. Crece en pastizales secos y yermos arenosos o pedregosos. Habita en la región mediterránea e islas Canarias. La recolecté a pocos metros del Fortín de la Restinga.

Paronychia capitata (L.) Lam. subsp. capitata (cariofiláceas)

Hierba perenne, de tallos postrados, a menudo muy enmarañados; de hojas pequeñas, lanceoladas, pubescentes; de flores ocultas por brácteas de aspecto níveo, con sépalos sin aristas y desiguales, agrupadas en glomérulos; y de frutos en utrículo. Crece en prados secos y laderas soleadas. Se encuentra dispersa por la región mediterránea. Cogí una muestra en el Atalayón.

\section{Phagnalon saxatile (L.) Cass. (compuestas)}

Planta subarbustiva, ramificada, de tallos ascendentes de hasta 50 $\mathrm{cm}$ de alto, lanosos; de hojas lineares (de 2 a $4 \mathrm{~mm}$ de anchura), verdosas por encima y lanosas por debajo, revolutas; de capítulos solitarios, con las brácteas finalment patentes o reflejas; y de frutos en aquenio provisto de vilano. Prospera en roquedales y taludes pedregosos, encarados al sol. Es frecuente en toda la región mediterránea. La recogí en el Atalayón, donde era abundante.

\section{Polygonum maritimum L. (poligonáceas)}

Hierba perenne, postrada; de cepa leñosa y tallos algo lignificados; de hojas estrechamente elípticas o casi ovales, con el margen revoluto; de ócreas (órganos envainadores formados por la fusión de las estípulas) hialinas y dilaceradas, con la base marrón rojiza; de flores pequeñas, blanquecinas, solitarias o en pequeños grupos axilares; y de frutos en aquenio, trígonos. Habita en playas y dunas litorales, como integrante de comunidades vegetales de la clase Ammophiletea. Se encuentra en muchas zonas templadas del hemisferio norte, siempre a la orilla del mar. La recolecté cerca de la aldea de Oulad Zahra, pero la he observado en toda la manga de la Mar Chica. 


\section{Pseudorlaya pumila (L.) Grande (umbelíferas)}

Hierba anual muy peluda, casi híspida, ramificada desde la base; de hojas dos o tres veces pinnatisectas; de flores blancas o de color púrpura claro, reunidas en umbelas compuestas; y de frutos de 7 a $23 \mathrm{~mm}$, con varias filas de espinas gloquidiadas, las laterales mayores que las dorsales. Es característica de la vegetación de dunas y arenales marítimos. Se extiende por todo el litoral mediterráneo y costas atlánticas de la Península Ibérica y Marruecos. La recolecté cerca del Fortín de la Restinga, pero la he observado a lo largo de toda la manga de la Mar Chica.

\section{Reichardia tingitana (L.) Roth (compuestas)}

Hierba normalmente anual, glabra; de hojas pinnatífidas o pinnatipartidas; de capítulos llevados por pedúnculos largos y algo engrosados en el ápice, con un involucro bastante grande (de 10 a $15 \mathrm{~mm}$ ) de brácteas ovales y de márgenes anchamente escariosos, y con lígulas amarillas pero de un púrpura oscuro en su base; y de frutos en aquenio, pequeños, con cuatro costillas transversalmente tuberculadas y provistos de un vilano sedoso. Prospera en yermos y herbazales ruderales, preferentemente sobre suelos arenosos. Su área de dispersión es muy grande: región mediterránea, Canarias, una extensa parte de Asia y también África del Sur. La herboricé cerca del Fortín de la Restinga.

Retama monosperma (L.) Boiss. subsp. bovei (Spach) Maire (leguminosas)

Arbusto de ramas con costillas longitudinales; de hojas efímeras; de flores blancas; y de frutos en legumbre ovoide, que continen una sola semilla. Medra en pinares, tarajales y matorrales costeros, casi siempre sobre arenas consolidadas. Se trata de una planta endémica del suroeste de la Península Ibérica y del norte de África, representada en el litoral mediterráneo marroquí por la subespecie bovei. La recogí sobre dunas fosilizadas, tanto al norte como al sur de la Bocana.

\section{Tamarix gallica L. (tamaricáceas)}

Árbol ramoso, glabro, de 2 a 8 metros de altura; de hojas escamosas, imbricadas, con pocas células secretoras; las flores, pequeñas y de color rosado, están agrupadas en racimos delgados (de 3 a $5 \mathrm{~mm}$ de anchura), cuyos raquis son glabros, no papilosos; los racimos, a su vez, están dispuestos en panículas en el extremo de las ramas; las brácteas 
florales son más cortas que los cálices correspondientes; los sépalos son poco o nada denticulados, y no son papilosos en el margen; y los frutos son cápsulas septicidas que contienen numerosas semillas, las cuales llevan un penacho de pelos. Crece sobre suelos salinos, sobre todo en el litoral, pero también en el interior. Se encuentra en el cuadrante suroccidental de Europa y en el cantón noroccidental de África. Es frecuente en las inmediaciones de la Mar Chica, aunque solamente poseo muestras del Atalayón y de Oulad Zahra. [4]

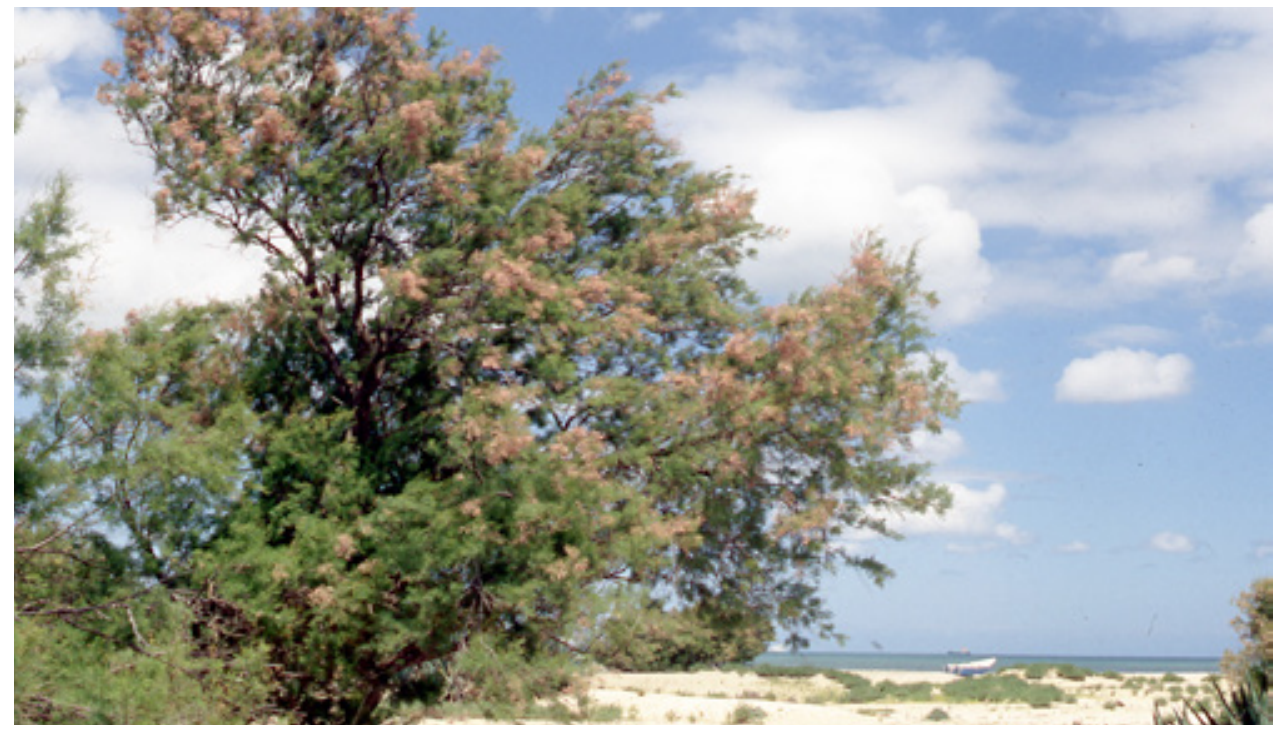

Fig.4. Tamarix gallica

\section{Tetragonolobus purpureus Moench (leguminosas)}

Hierba anual pubescente; de hojas trifolioladas y estipuladas; de flores solitarias o apareadas, bastante grandes (de 15 a $22 \mathrm{~mm}$ ), de color de púrpura, mucho más oscuro en la quilla; y de frutos en legumbre de sección casi cuadrada y con alas onduladas en las aristas, lampiños, a diferencia de las restantes partes de la planta. Aparece sobre sustratos diversos, formando parte de comunidades vegetales terofíticas de la clase Thero-Brachypodietea. Es propia del sur de la región mediterránea. En el ámbito de la Mar Chica, la recolecté en el Atalayón.

\section{Tolpis barbata (L.) Gaertner (compuestas)}

Hierba anual, más o menos ramificada; de hojas lobuladas, la mayoría arrosetadas; de capítulos sobre pedúnculos algo engrosados, con 
brácteas setáceas, rígidas e incurvadas; y de frutos en aquenio, negruzcos y escábridos, los externos con una corona de escamas y los internos con 2 a 5 setas, un poco más largas que el propio aquenio. Se da en comunidades de terófitos, preferentemente sobre terrenos arenosos. Se halla en toda la región mediterránea. La recogí cerca de la aldea de Oulad Zahra.

\section{Trifolium angustifolium L. (leguminosas)}

Hierba anual, pelosa, erecta, de 10 a $50 \mathrm{~cm}$ de altura; de hojas compuestas de tres foliolos estrechos (de 2 a $4 \mathrm{~mm}$ de anchura), con estípulas lanceoladas; de flores rosadas, con la corola de parecida longitud a la del cáliz, el cual es marcadamente ciliado y muestra 10 nervios o venas; las inflorescencias son glomérulos densos, terminales y pedunculados, de forma ovoide o cilíndrica; y los frutos son legumbres monospermas. Crece en prados terofíticos, orillas de caminos y parajes herbosos. Es una planta común en toda la región mediterránea y zonas próximas. La recolecté en el Atalayón.

\section{Trifolium ligusticum Balbis ex Loisel.}

Hierba anual, pelosa; de hojas alternas, trifolioladas, estipuladas, las inferiores con un largo peciolo; de flores pequeñas, rosadas, con el cáliz muy peloso, agrupadas en inflorescencias glomerulares; y de frutos en legumbre, pequeños, con una sola semilla. Vive en pedregales herbosos y en claros del matorral. Es una planta de las regiones mediterránea y macaronésica, y de algunas zonas del Próximo Oriente. La herboricé en el Atalayón.

\section{Trifolium tomentosum L. (leguminosas)}

Hierba anual, glabra excepto en los cálices; de hojas alternas, trifolioladas y estipuladas; de flores pequeñas, rosadas, con el cáliz finalmente muy hinchado y con una muy aparente nervadura reticulada, reunidas en glomérulos globosos; y de frutos en legumbre, pequeños e incluidos en el cáliz. Crece en herbazales, bordes de caminos y campos incultos. Se encuentra en las regiones mediterránea y macaronésica, y también en el suroeste de Asia. La recolecté en Tauima, cerca del antiguo aeródromo.

\section{Tripodion tetraphyllum (L.) Fourr. (leguminosas)}

Planta herbácea anual, pelosa; de hojas imparipinnadas, con el foliolo terminal mucho mayor, de figura elíptica y ligeramente mucronado; 
de flores amarillentas, con el cáliz acrescente y ventricoso; y de frutos en legumbre moniliforme, con dos semillas. Crece en herbazales, claros del matorral y márgenes de caminos, sobre terrenos calcáreos o arcillosos. Es una especie de distribución mediterránea, frecuente en todo Marruecos. La recolecté en el Atalayón.

\section{Urtica pilulifera L. (urticáceas)}

Hierba anual, con pelos urticantes; de hojas simples, opuestas, ovales o casi deltoides, de margen serrado y con un largo peciolo; de flores unisexuales de disposición monoica, las femeninas reunidas en inflorescencias esféricas largamente pedunculadas, y las masculinas en inflorescencias espiciformes laxas; y de frutos en aquenio. Medra en herbazales ruderales, campos y baldíos. Se extiende por la región mediterránea y el suroeste de Asia. La herboricé en Nador, junto a la depuradora.

\section{Urtica urens L. (urticáceas)}

Hierba anual, con pelos urticantes; de hojas simples, opuestas, ovales y fuertemente dentadas; de flores unisexuales agrupadas en racimos cortos, con muchas flores femeninas y pocas masculinas; y de frutos en aquenio. Se cría en ambientes ruderales, sobre suelos ricos en nitrógeno. Se halla en toda la región holártica, es decir, en las zonas templadas y frías del hemisferio norte. La recogí en el Atalayón.

\section{Valerianella discoidea (L.) Loisel (valerianáceas)}

Hierba anual, pequeña (de 4 a $25 \mathrm{~cm}$ de alto), de hojas lanceoladas y ligeramente incisas, de inflorescencias globosas (de 8 a $12 \mathrm{~mm}$ de diámetro) y de flores blanquecinas. Los frutos son aquenios densamente pelosos, apenas más largos que anchos, coronados por el cáliz acrescente y campanulado, con 6 o más lóbulos de forma triangular, aristados, uncinados e internamente pelosos. Aparece en prados secos, calveros, ribazos y barbechos. Es común en toda la región mediterránea. La recolecté en el flanco occidental del Atalayón, en un claro del matorral. 


\section{Bibliografía}

CASTROVIEJO, S et al. (edit.). (1986-2018). Flora iberica (vol. 1-21; falta 16-2 i 19). Madrid: Consejo Superior de Investigaciones Científicas.

FENNANE, M. et al. (edit.). (1999-2015). Flore pratique du Maroc (vol. 1-3). Rabat: Institut Scienifique.

GONZÁLEZ, J. A., GARCÍA, H. y CABO, J. M. (2003). La flora silvestre de Melilla. Melilla: Ciudad Autónoma de Melilla.

HERNÁNDEZ, A. M. (coord.). (2004). La Mar Chica, un gran espacio natural. Melilla: CD editado por los autores.

VALDÉS, B. et al. (edit.). (2002). Catalogue dels plantes vasculaires du nord du Maroc (vol. 1-2). Madrid: Consejo Superior de Investigaciones Científicas.

YUS, R. y CABO, J. M. (1986). Guía de la naturaleza de la región de Melilla. Melilla: Ayuntamiento de Melilla. 